\title{
Information Seeking and Collaborative Knowledge Creation: Exploring Collaborative Learning in Customer Service Work and Software Product Development
}

\author{
Anders I. Mørch, \\ InterMedia, University of Oslo \\ anders.morch@intermdia.uio.no
}

\begin{abstract}
Computer supported collaborative learning (CSCL) and e-learning at work (ELW) are two areas in computer-mediated learning. CSCL is a relatively focused research theme, but with few dedicated journals and a relative small group of core researchers. E-learning research is reported in a variety of journals and magazines, but lacks a well-defined research agenda. CSCL is about computer support for two or more people to engage in collaborative inquiry (co-located or distant) with teaching and learning as primary activities. ELW is about providing employees with timely access to information for carrying out work, where work is the primary activity. Based on a survey of previous research it is argued that it is a challenge for CSCL to integrate individual and collaborative learning and for ELW to integrate work and learning. These challenges are explored in two case studies, the first focused on customer service work and the second software product development. The findings are discussed in terms of providing opportunities for CSCL at work: multiple channels for access to information, and means for employees and customers to engage in collaborative knowledge creation processes.
\end{abstract}

Keywords Collaborative knowledge creation * CSCL * CSCW * E-learning at work * Information seeking * Secondary work * Workplace learning

\section{Introduction: Challenges for CSCL at work}

Challenges for Computer supported collaborative learning (CSCL) at work are formulated as dilemmas, leading to research questions and opportunities for resolving them. Dilemmas reveal tensions and disturbances that require development and learning; they can help to advance the current state of knowledge (Engeström, 2011). In addition, dilemmas reveal problems for which there are no fixed answers (Fischer, 2003). This could be because the situations in which the problems occur are poorly understood or because there are multiple, alternative solutions.

In this chapter, two general dilemmas are addressed. One is organizational and concerns the gap between work and learning, and the other the lack of a conceptual framework for integrating individual and collaborate learning. I claim the two 
challenges are deeply rooted both in CSCL and e-learning at work (ELW) given the large body of previous research attempting to resolve them. Previous efforts have branched computer-mediated learning into many sub-areas. This chapter argues that the time is ripe to address them afresh with the advent of new perspectives like CSCL at work (this volume), new technologies like social media (Kaplan \& Haenlein, 2010), and emerging practices like cultures of participation (Jenkins, 2009; Fischer, 2011). I report from our efforts at exploring the challenges in two case studies: one involves customer service work in an oil company and the other involves collaborative knowledge creation in a software house, and I propose a set of research questions for the emerging field of CSCL at work.

First dilemma - learning and work: Educational institutions have been criticized for being preoccupied with theories and not being sufficiently in contact with the world of business, corporate finance, engineering, health care, marketing, manufacturing, national policy, public service, and so forth. The complaint is that university students have general and subject-specific competency but lack the skills necessary for applying the knowledge in different settings. To bridge this gap between theory and practice, educational institutions have adopted instructional methods modeled after problem solving in the professional world. These methods are problem-based learning, project-based learning, and case-based learning to name a few. The basic idea is that students will gain a deeper understanding of a knowledge domain if they engage in a practice-like process in the domain, generating their own problems, proposing tentative answers and searching for deepening knowledge collaboratively. This is a common teaching method in professional degree programs in engineering, medicine, law, etc. throughout the world.

The adoption of new models from other domains is not unique to educational institutions. Early adopters and trendsetters in society emerge from the creative class of knowledge workers like university graduates (Florida, 2002). Their proficiency with new technology creates a pressure for many companies to adopt new participative learning practices. Furthermore, educational institutions will adopt best practices from each other. An example of relevance for this study is the educational reforms in Scandinavia in the early 1970s that introduced collaborative learning (e.g., group work), open schools (adaptive classrooms), and techniques to stimulate creativity. These are, arguably, distinctive features of the Scandinavian school system. Most recently, educators in Denmark have exported the "Scandinavian model" to schools in China in a joint effort to experiment with the integration of collaborative and individual learning in order to develop an educational model that is better fit for each country and for a global society (Gräs, 2011). It is too early to speculate about what results this initiative will bring, but it exemplifies an important trend that is addressed in this chapter: namely, experimental efforts to combine practices that previously have been thought of as incommensurable or difficult to combine. This leads to the next dilemma for CSCL at work:

Second dilemma - collaborative and individual learning: In Sfard's (1998) influential survey of theories of learning, she introduces two metaphors of learning to distinguish among them, acquisition and participation. This is roughly equivalent to the distinction of individual and collaborative learning, respectively. 
The acquisition metaphor entails that learning means to gain possession of some commodity, transmitted from a teacher to a learner during instruction, where the aim is development of concepts and acquisition of knowledge (Sfard, 1998). According to the participation metaphor, the context for learning is important, in particular social interaction and community building. The ability to communicate in the language of the community is essential to learning according to this metaphor (Sfard, 1998). The duality of the metaphors, together with the slightly negative connotation associated with them, indicate that they refer to fragmented knowledge. How to achieve the synergy of individual and collaborative learning is an issue that has received much debate in the learning sciences, and particularity in CSCL (Stahl, Koschmann \& Suthers, 2006). Broadly speaking, there are two main positions on the issue: the "cognitive" and the "social." Their difference hinges on how the duality is balanced and how each position is given weight and prioritized. The social position holds that learning is mediated by dialog (spoken interaction). The cognitive position treats the social as a background weakly connected to learning. It is focused on internalization as a process of perception, thought, and reasoning.

To transcend the dichotomy represented by the two positions, they must be combined in synergistic ways. Three approaches are viable: 1) start from the "social plane" and reach inward (Vygotsky, 1978); 2) start from the "cognitive system" and extend outward (Simon, 1997); or 3) identify common objects on the intersection of the two planes and make the objects building blocks for further development (translation, transformation, expansion, etc.). Spoken language is on the interface: audible in speech and silent in thought (Wertsch, 1991; Rommetveit, 1992), as well as the other tools that allow us to use, modify, and extend knowledge objects and physical things in our immediate surroundings.

Two initiatives in the CSCL community towards a synergy following the first approach are briefly presented. Enyedy \& Hoadley (2006) propose two types of computer interfaces, one a communication interface for participation learning and one information interface for acquisition learning. An inquiry model they refer to as "progressive discourse" is described as "individuals take up what is said by others, compare it to their own understanding, and respond to these ideas, pushing the collective discourse forward, and at the same time extending one's own thinking" (Enyedy \& Hoadley, 2006, p. 416). Enyedy and Hoadley have focused more on supporting collective discourse (participation learning) than extending one's own thinking, and the interfaces they propose have much in common with group inquiry environments like Future Learning Environment (FLE) (Leinonen et al., 2002). In the KP-Lab project (Moen, Mørch, \& Paavola, 2012) various techniques have been proposed to integrate Sfard's two metaphors in novel ways, including developing new kinds of interfaces, proposing new concepts, and studying practice transformation in educational institutions and workplaces. The notion of "trialogical," was coined by Paavola \& Hakkarainen (2005) as a third approach to learning, refers to the integration of monologue (as in acquisition) and dialogue (as in participation). The dialogical sub process is the sum of individuals' contribution to collaborative knowledge creation (i.e., communication taking place while developing a shared artifact together and negotiating what the common goal should be). Monologue means the internalization of the common knowledge 
collaboratively created, in an effort to extend one's own thinking. The results of a trialogical process are shared knowledge objects and concrete artifacts (Moen, Mørch, \& Paavola, 2012).

\section{Review of related work}

In popular press and some policy documents, CSCL and e-learning sometimes are treated as the same (online distance education). Elsewhere, CSCL has been misunderstood and called a specific methodology (a subcategory) of e-learning (Stahl, Koschmann, \& Suthers, 2006). In this chapter, I focus on the differences of CSCL and e-learning. Broadly speaking, and according to the challenges just raised, CSCL is about collaborative learning applied in educational settings, whereas ELW is about computer support for individual learning applied in workplace settings. However, this comparison is very rough and will be considerably elaborated below, according to goals, perspectives, computer support, and research methods.

\section{Computer supported collaborative learning}

Learning in CSCL is characterized by knowledge sharing and knowledge construction in groups, which are often modeled as group inquiry processes (Bereiter et al., 1997; Hakkarainen, 2003; Stahl 2006). The setting for CSCL can range from remote collaboration in virtual worlds (like Second Life) or a collaborative inquiry environment (like Knowledge Forum) (Bereiter et al., 1997) to two or more people located around the same computer to solve a mathematics problem in the classroom (Stahl, 2006). It is the knowledge that is constructed together by the members in the group, and the shared meaning making process that aims to reach it that are the main objects of study for CSCL researchers. The individual learning that may be required to participate in a collaborative learning activity and the individual learning that may occur as a result are typically not part of CSCL research because "CSCL locates learning in meaning negotiation carried out in the social world rather than in the individuals' heads" (Stahl, Koschmann, \& Suthers, 2008, p. 9). However, the relationship between individual and collaborative learning is debated in the CSCL community because the two types of learning are closely intertwined. The debate has been associated with the multiple interpretations of Vygotsky's social learning theory, and the integration of collaboration and learning in social learning activities.

Vygotsky (1978) proposed the "law of genetic development," in which he claimed that learning occurs on two planes: first the social plane and then the individual. Furthermore, he proposed the idea that there is a transformation between the two planes (iterative and incremental) carried out in productive dialogs among peers and more capable persons, and mediated by cultural artifacts (Wertsch, 1991). Unfortunately, Vygotsky was not able to complete the research he set out to do in his own lifetime. He outlined the critical issues, formulated hypotheses, and discussed tentative answers by comparing and refuting contemporary research (prior to 1934). His students (e.g., Leontiev and Luria) researched the two planes more rigorously in their own terms, but they did not 
manage to reconnect the two branches of research. A reason for this could be the challenge entailed by efforts to bridge social learning and individual (neuropsychological) learning, each having its own set of research methods and reference systems (theories, models, etc.).

Arnseth and Ludvigsen (2006) have identified and discussed the similarities and differences between two approaches to CSCL according to research approaches, which they refer to as systematic and dialogical. The systematic approach in CSCL aims to identify independent collaboration variables (e.g., group size, composition, nature of common task, type of mediating artifact) and to find out if there are interdependencies and effects on individual learning (Dillenbourg et al., 1996). The unit of analysis is the individual learner. Acquisition and transfer are two key processes. The dialogic approach in CSCL is based on the idea that learning is a socially organized activity. The unit of analysis is a group of individuals interacting to accomplish a shared learning objective. Key processes are interaction, social context, and cultural mediation (by various tools, including ICT) (Rommetveit, 1992; Wertsch, 1991; Stahl, 2006; Ludvigsen \& Mørch, 2010). It is through talk and interaction with others that understanding is measured with the dialogical approach. Common research methods following the dialogical approach are ethnographic research, ethnomethodology, and discourse and interaction analysis (e.g., Jordan and Henderson, 1995).

Design research in CSCL ranges from pedagogical interventions in classrooms using methods like design experiments (Collins, Joseph \& Bielaczyc, 2004; Krange \& Ludvigsen, 2009) to various means of scaffolding collaborative knowledge construction and knowledge sharing with computer support, such as organizing collaboration by interaction scripts (Fischer et al., 2007), critiquing and advice giving (Fischer et al., 1991; Mørch, Jondahl \& Dolonen, 2005), multiple representations and visualizations (Suthers \& Hundhausen, 2003), and complex monitoring and interaction analysis with the use of AI techniques (Hoppe, Ogata \& Soller, 2007). Comparing user interaction data with desired models of collaboration like those defined in scientific inquiry can generate these forms of automated feedback. Examples of scientific (research like) inquiry models in CSCL are knowledge building (Bereiter et al., 1997; Law, 2002; Stahl 2006), progressive inquiry (Hakkarainen, 2003) and progressive discourse (Enyedy \& Hoadley, 2006). The pedagogical interface agents developed in the DoCTA project in Norway (Mørch, Jondahl \& Dolonen, 2005) were designed to support progressive inquiry in FLE (Leinonen et al., 2002). The feedback from these agents was formulated as advice for how students could be more active in the knowledge-building forum and how to add new notes (contributions) based on the notes already posted. Computerbased critics integrated with design environments (Fischer et al., 1991) have inspired the pedagogical agents in FLE.

In sum, the role of software (including the AI work) in all the work reported above is to support, not replace, humans in collaborative knowledge creation processes. Of the CSCL research reported to this date, most of it has been carried out in or in close proximity to educational institutions, and there is a discrepancy between a small number of core researchers and a large body of international researchers thinly spread out (Kienle \& Wessner, 2005); and, to the best of my knowledge, there are few studies of CSCL reported in workplace learning journals. 


\section{E-learning at work}

The research area of e-learning at work (ELW) is fragmented and reported in many journals and magazines. The current review takes a bird eye's view of this research and supplements it with more detailed studies in the implementation of e-learning in specific organizations. Cheng et al. (2012) have conducted a thematic analysis of 736 published articles in 23 journals, accepting papers on "workplace e-learning" in the period from 2000 to 2010. The methods employed were bibliometric techniques and keyword visualization (co-word analysis, hierarchic clustering, network graph diagramming). Elsevier's Scopus database was chosen as the data source (all documents were electronically available). The corpus was obtained by a search with the keywords "e-learning" and "distance learning" in the database. The resulting dataset of 736 articles were clustered based on the articles' keywords, through a series of data processing steps, including constructing a keyword cooccurrence matrix. After operating on this matrix to reduce and group it, the analysis yielded six clusters of keywords, which were labeled into six topics by the authors: 1) technology-enhanced learning, 2) computer-mediated knowledge and information management, 3) adult education, 4) organizational learning and management with technology support, 5) performance support systems, and 6) technology adoption and impact. Other general findings from the literature on elearning at work are that it is predominantly focused on technology and cost savings (Servage, 2005), and that it often suffers from poor application of scientific knowledge from organization studies and learning theories (Tynjälä \& Häkkinen, 2005).

A detailed case study of one organization's implementation of a suite of elearning applications was carried out as part of a $\mathrm{PhD}$ dissertation in Norway (Netteland, 2008) and reported in the literature (Netteland, Wasson \& Mørch, 2007). Netteland has studied the implementation process of e-learning in a large telecom company in Norway over a period of four years. The Company's HR department had a vision of organizational learning captured by the slogan "empower the single employee to take responsibility for the company's development and growth" (Netteland, Wasson \& Mørch, 2007). This is a simplification of an application of the organizational learning theory of Wenger (2000) referred to as social learning systems. In a social learning system, employees are the central actors. Engagement, imagination and alignment are three terms used to differentiate among the types of participation in a social learning system (Wenger, 2000). Engagement is learning that is close to the task at hand, and alignment is learning that is associated with the shared goals of the company. Imagination is learning associated with representations of the local situation for the purpose of reflection and self-regulation. Netteland (2008) has identified a resistance met by the HR department when implementing the organizational learning vision during the e-learning adoption process. Her study identified six challenges (tensions or disturbances) for e-learning in this type of environment, three of which are specific to the adoption process: 1) management control, 2) technical infrastructure for learning, and 3) execution of implementation tasks and three of which are broader in scope: 1) information sharing (lack of information sharing hinders critical mass of users), 2) allocation of time (time for e-learning must be available during everyday work), and 3) relevance to work and previous 
knowledge (otherwise employees will not be motivated or see the benefit of elearning, and seek out other means for getting access to required information). It is worth noting that the participation approach to learning (Sfard, 1998; Wenger, 2000) failed in this organization as the e-learning system was not compatible with the participation metaphor. The e-learning applications introduced in the company were designed according to the acquisition metaphor (Netteland, 2008).

In a study of using a collaborative learning environment in workplace learning, Wang (2011) has addressed challenges associated with the technical infrastructure of e-learning and found that the organization failed because the e-learning environment took into account neither organizational goals (alignment) or individual needs (engagement), a mismatch that contributed to a predominantly technology-driven approach during implementation. Lack of relevance to work is another recurring issue that has been reported in related work. Fischer has coined the term "learning on demand" (Fischer, 1995) to propose a solution to a problem he refers to as "making information relevant to the task at hand" (Fischer et al., 1991; Fischer 1995). According to Fischer (1995) and Mørch, Engen, and Åsand (2004), learning on demand can be approached by a better integration of computersupported learning with the work tools employees rely on in their daily work. When learning at work is treated as an extension of daily work rather than an activity to be done elsewhere, e-learning applications can be designed to be more relevant for work and responsible to user requirements by being accessible from specific situations requiring learning or delivered as information chunks compatible with work performance abilities and demands (Mørch \& Engen 2008).

\section{Summary, comparison, and contrast}

The brief survey of two areas of computer-mediated learning shows that there are indeed major differences between CSCL and ELW. The main challenge for CSCL is to provide integrated support for individual and collaborative learning, and a secondary challenge is to provide a better integration of education and work, as very few CSCL studies have been carried out in workplace settings. On the other hand, researchers in workplace learning have ignored the complexity of implementation and adaptation of computer mediation. In ELW, the main challenge is therefore integration of e-learning in daily work, and the secondary challenge is to provide better support for collaborative and individual learning

Emerging, common themes in CSCL and ELW are web browsers and social networking technology as platforms for social learning environments. Moreover, both CSCL and ELW have strived towards better scientific foundation for their research. This is generally accepted (but not agreed upon) in CSCL, and an emerging theme in ELW. Two themes that do not seem to have much in common are technology adoption and research methods. The introduction of a new learning technology in a business context is sometimes a costly endeavor that may last several years. Models and methods to support the adoption process are diffusion of innovation (Rogers, 2003), participatory design (Mørch, Engen \& Åsand, 2004), and evolutionary application development (Mørch, Nygård, \& Ludvigsen, 2009). On the other hand, when a new learning technology is introduced in a classroom, it is often profiled as a "design experiment," a relatively short-lived innovation 
(weeks to months). The aim of a design experiment is bring new research informed by theory into use rather than sustaining an innovation over time (e.g. after the research projects have ended). Finally, research methods in CSCL tend to be more rigorous than those used in ELW, and the research conferences on CSCL and the related areas of the learning sciences are more prestigious than those on ELW.

\section{Two case studies in CSCL at work}

I will now report from two case studies carried out in our research group, ICT and Learning at Work, during the past 10 years. The aim is to identify opportunities for CSCL at work by proposing solutions to the challenges introduced above. The first case is from a three-year Norwegian project, Learning at Work (LAP in Norwegian), carried out between 2001 and 2004. This project was organized as a consortium of two companies in the service sector (oil company and accounting firm), the Federation of Norwegian Commercial and Service Enterprises, and three research institutes (one being the University of Oslo). The project had the aim to develop methods for "learning on demand" (Fischer, 1995) in customer service work, and therefore addresses the challenge of integrating work and learning. The second case is an empirical study of the interaction of end-user development (EUD) and professional software development (PSD) in a Norwegian software house. It was part of a large European project called Knowledge Practices Laboratory (KP$\mathrm{Lab}$ ) carried out between 2006 and 2011. The common theme explored in this project is collaborative knowledge creation (Paavola \& Hakkarainen, 2005; Moen, Mørch, \& Paavola, 2012), which resulted in a set of tools and a model of collaborative learning based on the trialogical approach (Paavola \& Hakkarainen, 2005). The main challenge addressed in this project is to transcend the dichotomy of learning, described by the two metaphors of learning, acquisition and participation, proposed by Sfard (1998). Each case is organized into four subsections: context, methods, findings, and analysis.

\section{Information seeking in customer service work}

Context: A goal of the LAP project was to introduce web-based learning resources in the two companies. One of the companies is the gasoline station division of an oil company (hereafter called ServiceCompany). The need for learning at work in service work is evident, as skills for performance when serving customers are high. Gasoline stations in Norway are effectively small supermarkets and fast food snack bars, in addition to being outlets for automobile products and gasoline. The employees in these multi purpose service centers are faced with a large inventory that contains many different products and services they need to know about. Staff members are often young and inexperienced, but there are older employees with few skills in using computers. The combination of high demands on quality of customer interaction, the rise in the number of products and services an employee needs to know about to successfully perform, the widespread adoption of mobile and ubiquitous computing devices, and a broad learner group have given rise to new demands on workplace learning. 
The following scenario provides an example of a situation requiring a new type of learning at work. A customer is asking an attendant for help measuring the car's antifreeze level on the liquid cooling system, but the attendant cannot respond to the customer's request. He or she then asks a more experienced colleague at the station to demonstrate the procedure for the attendant. Therefore, learning can, in this context, be seen as a by-product or side effect of everyday work, not as an end in and of itself. The training programs provided by the HR department of the company can identify these learning needs and provide programs to support it, at a general level.

Methods: A research team from our university participated in the design and organizational implementation of the new web-based learning application, 'web portal' for short (Mørch, Engen \& Åsand, 2004; Mørch \& Skaanes, 2010). The research question we set out to address was: 1) how does the portal integrate with existing ways of seeking information in everyday work? and 2) how can we conceptualize learning at work in terms of primary work? During the early phases of the project, we made extensive use of participatory design techniques to involve future users (employees) in the process of designing their future workplace. It started with earning scenarios and mock-ups that were incorporated to envision the integration of work and learning (Figure 1). The final result was the field deployment of a web portal at 230 service stations. To reach the final result six versions of the system were made and four were tested with end users. The first version is depicted in Figure 1. It is a mock up of a portable information display created in a participatory design workshop with representatives of the end users (Mørch, Engen, \& Åsand, 2004), and the final one was a solution integrated with the cash register created by the ServiceCompany and shown in Figure 2 (Mørch \& Skaanes, 2010).

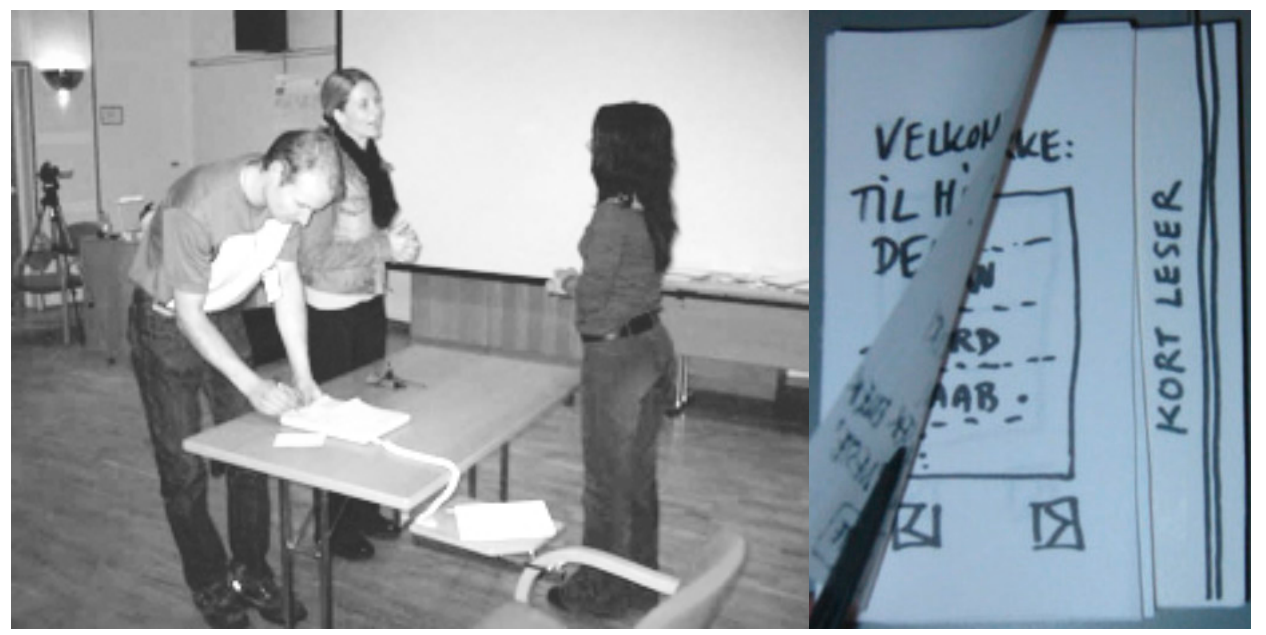

Figure 1: Left: Playing a work-oriented script with the aid of a mock-up to resolve a breakdown (customer waiting in line is helping himself by consulting a semi-mobile information display). Right: Mock-up with Post-it notes and hand drawing to simulate functionality of handheld device.

The portal adoption process lasted for 14 months and 230 service stations were involved. The data we report on was collected between the $3^{\text {rd }}$ and $6^{\text {th }}$ month of the adoption process, during which the portal had been installed at 25 stations. We collected data from multiple sources: field observations, online questionnaires and interviews. A mixed methods approach was used to triangulate the data. The 
questionnaire was sent to the 25 stations. The items in the questionnaire concerned information-seeking strategies employed during daily work as this was judged to be an important method for integrating work and learning, and thirty-four respondents completed the survey.

The majority of the respondents were attendants in the age group 20-29 (three station managers and regional manager were older). The average number of years working for the company was three. The use of the system was not mandated during this period, but the station managers encouraged the attendants to use it.

Findings: The new web portal was implemented more or less in competition with already well-functioning technologies for interpersonal communication; before the introduction of the portal, the attendants had to make use of a range of resources for accessing information to support their work. We asked the employees at several stations how they would get access to the relevant information if none of the self-help strategies applied. A representative answer was: "We just pick up the telephone and call a nearby ServiceCompany station." Results from the survey showed that $81 \%$ of the respondents reported that asking a colleague was the most useful approach when seeking information. Other frequently used resources of information were paper catalogs $(58 \%)$ and staff meetings $(50 \%)$. Paper catalogs are vendor specific product manuals containing automobile parts and assembly instructions. The staff meeting was a weekly forum for information exchange where questions could be asked. During these meetings the attendants would be informed about the introduction of new products. In addition, 38\% of the respondents said they would call a colleague at home if he or she encountered problems that no one present could answer. The station manager and the assistant manager were the two people most likely to be contacted in this way (Mørch and Skaanes, 2010). The table in Figure 2 gives an overview of the information seeking methods the attendants made use of, ranked according to frequency of use.

After the portal was introduced, $46 \%$ of the respondents said they stopped using one or more of the older methods. The remaining $54 \%$ of the respondents said they continued to use the older methods despite the availability of the portal, and several employees preferred to use the paper catalogs instead of the computerized display in order to find the required information. According to several of the attendants, it was important to have alternative means for accomplishing daily work. However, there are management plans to terminate the production of those methods that are too costly to produce and those that serve only one function.

Analysis: The findings are discussed in terms of learning on demand (Fischer, 2005), social learning systems (Wenger, 2000) and "secondary work," a new concept for work-integrated learning related to articulation work (Strauss, 1988). 


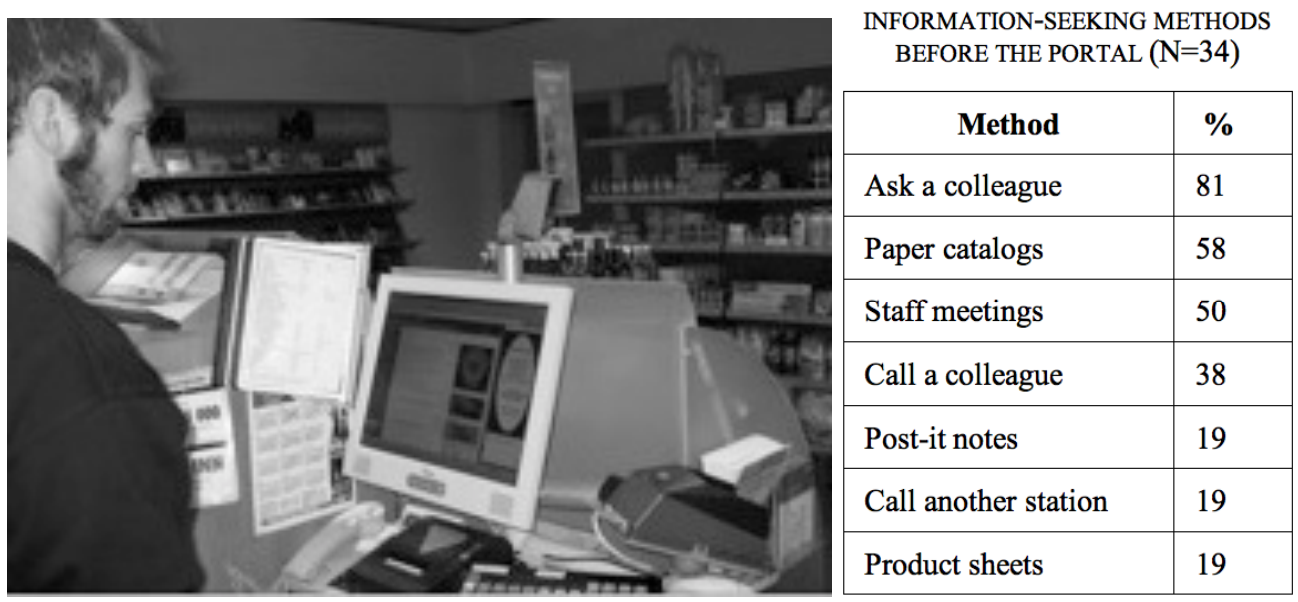

Figure 2: Left: The latest (fourth) prototype of ServiceCompany's web portal is integrated with the cash register, as two keyboards sharing the same screen ad computer. Right: Information seeking preferences before the portal was installed, and alternative means to find information when the answer is not known when interacting with customers at the ServiceCompany.

As the web portal went through several rounds of revision, we saw a shift in the station attendants' view of the portal, from a performance support system for small, geographically dispersed groups toward a participation tool for communication and information sharing for the entire company. This was an aim of the ServiceCompany, and evident to us (researchers) after the third prototype was installed, i.e. that the company wanted a shared portal for the entire organization. The end result could be seen in two different ways: 1) as a (partially completed) web-based learning environment supporting workplace learning according to the learning-on-demand strategy (Fischer, 1995), and 2) as a centralized informationsharing system emerging as a new form of work-integrated organizational learning. From an organizational learning point of view (Wenger, 2000), we saw a shift from local engagement to an alignment with the company's overall profile and shared values. The hands-on, work-oriented material of the mock-ups and role-playing sessions (see Figure 1) created a close connection with the operations of the first prototype, thus resulting in a higher level of engagement than we have seen with the third and fourth prototypes. On the other hand, the third and fourth prototypes have more durability due to corporate backing (see Figure 2).

When analyzing the work in the service stations, we could group the work into three categories: 1) primary work, 2) secondary work, and 3) gap-closing (Mørch \& Skaanes, 2010). Secondary work and gap closing are our main concerns here as they provide a vocabulary for conceptualizing work-integrated learning. Primary work refers to the main tasks to be accomplished during a workday, and these tasks are often written in a work description. Secondary work supports and augments primary work and comes to the foreground when the work is analyzed in detail or is otherwise disrupted and becomes an object of reflection. Secondary work is therefore a kind of articulation work (Strauss, 1987), but differ in its focus on information seeking behavior. The boundary between primary work and secondary work is not fixed, but dynamically changing and porous. The border changes when secondary work is taken up in primary work and when old work routines dissolve. 
In the ServiceCompany, primary work is serving customers and ordering out-ofstock items, alternating between a counter with cash register and a back office with a desktop computer. This work is periodically updated to reflect the demands of society in terms of customer needs, and to promote a certain image of ServiceCompany to the outside world about its priorities. Secondary work is often the source for updates to primary work because it is more responsive to new innovations and less rigid than explicit work descriptions. Information seeking was identified to be the main secondary work method. It was used to find required information to carry out primary work tasks. Furthermore, access to information to answer everyday questions has increased as a result of the ServiceCompany's continual effort to expand into other market segments (small goods retailing and hot food catering). The attendants must continually adopt the new methods and practices introduced with new business areas whenever the older ones become unavailable for further use.

The challenge explored is the gap between work and learning in computermediated workplace learning. The research questions raised in the study were: 1) how does the portal integrate with existing ways of seeking information at work, and 2) how can we conceptualize learning at work in terms of primary work? First, the portal provides access to required information by web search, but only about half of the participants in our study preferred it to the existing methods; in other words, it has not been fully integrated into daily work practices in the ServiceCompany. The employees rely on other information-seeking methods they are already familiar with (e.g. contacting colleagues within and across service stations). In this regard we provide new insight into the use of multiple information-seeking strategies in everyday work. Web search with the portal is one of several sociocultural approaches to seek and access information.

Second, the study identifies web-based information seeking as a type of secondary work. Although information seeking is already supported by existing (non-computerized) methods, the new web portal was preferred by half of the users we surveyed. In this regard, it seems a promising approach to bridge the gap between primary work and secondary work to accomplish required tasks. Gap closing work and learning by web-based information seeking means to organize work so that accessing information with a computer becomes a natural, nondisruptive part of everyday work (Mørch \& Skaanes, 2010). The learning scenario that served as one of the inputs for the design of the web portal was informed by the theory of learning on demand (Fischer, 1995).

However, there is a limit to gap closing work and learning. As mentioned earlier, the portal had been through a series of iterations before it was integrated with the cash register. The version immediately preceding it was a laptop with a similar user interface, but placed at the end of the cash register counter. Based on an evaluation of this configuration, it was concluded that its adoption as combined work and learning support was unsuccessful (Mørch \& Skaanes, 2010). The portal was barely used during this stage of development, and one reason for this was that it was located too far away from where the "action" (primary work) took place. The developers of the latest (5th) version of the portal learned from this and brought the portal closer to the cash register. This resolved the problem, but with the unanticipated consequence of bringing the portal "too near" to where the action is. 
Based on observation and interviews, it became clear that some of the attendants avoided the portal because it could interfere with the operation of the cash register. They were concerned that the cash register would stop working if they crashed the portal. The two systems were running on the same computer (with separate screens and keyboards). This was an unacceptable solution to the attendants, since primary work is more important to accomplish, even though avoiding the portal could lead to sub-optimal customer services. The lesson we have learned from this is that when secondary work interferes with primary work, the employees often switch to another secondary work strategy and resort to (sometimes sub optimal) alternatives. All of the existing information-seeking seemed to follow the same pattern: "nearby without interfering." The heuristic suggests that the cash register and the information/web-search display should be near enough to each other to allow for easy access from one to the other, but not too close that they infer with each other's internal workings.

\section{Collaborative knowledge creation in software product development}

Context: In the KP-Lab project, several application domains for knowledge creation were studied, but only a few were in a business context. The setting for this case is a small software house manufacturing project-planning tools (Mørch \& Andersen, 2010; Mørch, Nygård \& Ludvigsen, 2009). The company develops and sells its project planning software in the Nordic oil and gas industry and provides consultancy services, training, and support for the users of these tools. The researchers from InterMedia were invited into the company to give advice on their knowledge management practices for customer relations.

The company is known for their customer-initiated product development approach - that is, for close interaction with customer to develop tailor-made solutions (Andersen, 2008; Nygård \& Mørch, 2007). Customers are requested and encouraged to report usability problems and innovative uses; and some of the most skilled users also assist in end-user development (adaptation) of the company's products. The developers offer communication and information sharing tools for customer interaction, which has been stimulated through long-term relationships (maintenance contracts) and user forums. The main meeting ground is an annual showcase in which customers are invited to communicate with the company's employees.

Methods: Understanding the transitions from specific (adaptation) development to general (product line) development and back again have been one of our research questions (Mørch, Nygård, \& Ludvigsen, 2009). One of the objectives became to construct a model of "mutual development" between customers and professional developers as seen from an end-user development perspective-i.e., how there is a mutual dependency between end-user developers and professional developers with regards to proposing and making changes to the products, mediated by the company's software products and communication and information sharing tools (Andersen \& Mørch, 2009). Communication and information sharing tools started with the telephone then were supplemented by email, later extending to a Helpdesk interface, then a Customer Relationship Management (CRM) system, and, most recently, a Web 2.0 prototype created by the research team (Mørch \& Andersen, 
2010). The background for the Web prototype was to design a portal to organize the rapid growth of information and to improve the communication within the company and towards its customers.

We used a qualitative approach as part of a case study. Methods employed were open-ended interviews, focus groups and participant observations. Moreover, we used audio and video recorders to gather the data. We followed a grounded theory approach to categorize data (open coding and template matching), iterating between data and preliminary categories in multiple rounds. The empirical material consists of interview data and a video-recorded meeting with key stakeholders (developers and users).

Findings: When we interviewed the respondents (developers and customers), they related historical events connected to some external organizations the company does business with, in particular an oil company and an engineering company. Some of these events led to major changes in the company, including the creation of two new products, Planner and Microsoft Project Extension (MPX). However, most of the external events led to minor changes, producing only gradual improvements and continuation of existing products. Figure 3 shows a schematic overview of the major events that have influenced product line development in the company (Mørch, Nygård, \& Ludvigsen, 2009).

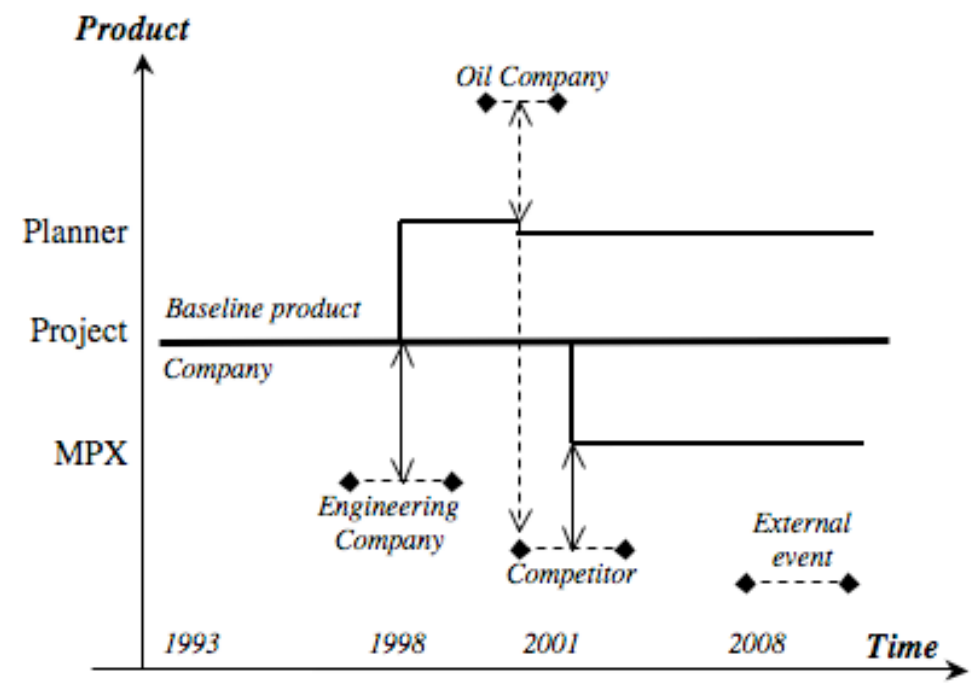

Figure 3: Software product line in the company studied. It depicts a family of software products starting with Project (a project planning software tool), which spawned two subsequent products, Planner (improved GUI) and MPX (Windows application), partially influenced by external events

The interview extract below illustrates a developer's view of user participation in adaptation of one of the company's products. The extract is from an interview with the head of support in the company, who is also involved in sales, development, and management. The interviewer focuses her questions around how user participation is initiated in practice, and the respondent refers to one of the products to exemplify user participation. 
Interviewer: Are there any customers that have participated in the development of your products?

Respondent: [...]Statoil [oil company in Figure 3] is an example. When we delivered version 3 of Planner, Statoil was a major initiator of the development. Much of what we incorporate in our products comes from our customers.

Interviewer: How do you receive customer requests, how is the process accomplished?

Respondent: Customers send us a wish list for new functionality or modifications to existing functionality. During development, if [the request for new functionality] seems reasonable, e.g. if others are asking for it, if it is an area we should look closer into and maybe look at in a broader perspective. For example, if you are writing reports and [someone] wants new functionality, we include it because we are already in there [altering the report-module in the product]. This enables late requests to be taken into account, assuming it doesn't have side effects requiring changes to many of the other modules in the product.

The interviewer asks the respondent how customers have participated in development activity. The respondent explains how one of their main customers is an active contributor to new ideas for development, and he exemplifies this by referring to one specific version of the project management tool Planner (see Figure 3). He later generalizes this ("Much of what we incorporate in our products comes from our customers"). The interviewer goes on to ask how improvement requests are received. The critical factors dealing with request processing include whether or not the request is judged to be important for the task at hand, how much extra work is required to incorporate it, and to what extent it is restricted to a well-defined area in the software code. This indicates two levels of development (customer and company): each with its own time scale and change rhythms. The discrepancy among the levels is best reconciled when specific requests for change align with the company's internal development cycles.

Analysis: We identified the sub-processes of the product development process studied, and ended up with the following five categories (sub-processes) of customer-initiated product development (abbreviated here, see Andersen \& Mørch, 2009):

- Adaptation: This is when a customer requests an improvement to an existing product and the company chooses to fulfill that request, which becomes an adaptation just for this customer. Sometimes, the customer has to pay for this, sometimes not.

- Generalization: This occurs when a new version of an existing product is released and is available to more than just one customer.

- Improvement Request: This is when customers make a request from the company for extra functionality, or to report bugs and usability problems, which are viewed from the customers' perspectives.

- Specialization: This is when the professional developers at the company create in-house builds. This could potentially result in new features, but most often it entails removing bugs, reorganizing program modules, and perfecting the product when time allows

- Tailoring: This is about active end-users (customizers, super users, local developers) who make adaptations on their own 
We justified these various stages using data extracts and analysis (Andersen \& Mørch, 2009; Mørch, Nygård, \& Ludvigsen, 2009), one of which is shown above. Our findings are summarized in Figure 4, our first attempt to construct a model that integrates professional development and end-user development. There is an implicit classification scheme of improvement requests that helps to filter a user contribution. When received by the company, it will first be classified as good, possible, or bad (Andersen \& Mørch 2009). A good suggestion is accepted as is. A possible suggestion must be accompanied with payment, and a bad suggestion is rejected outright.

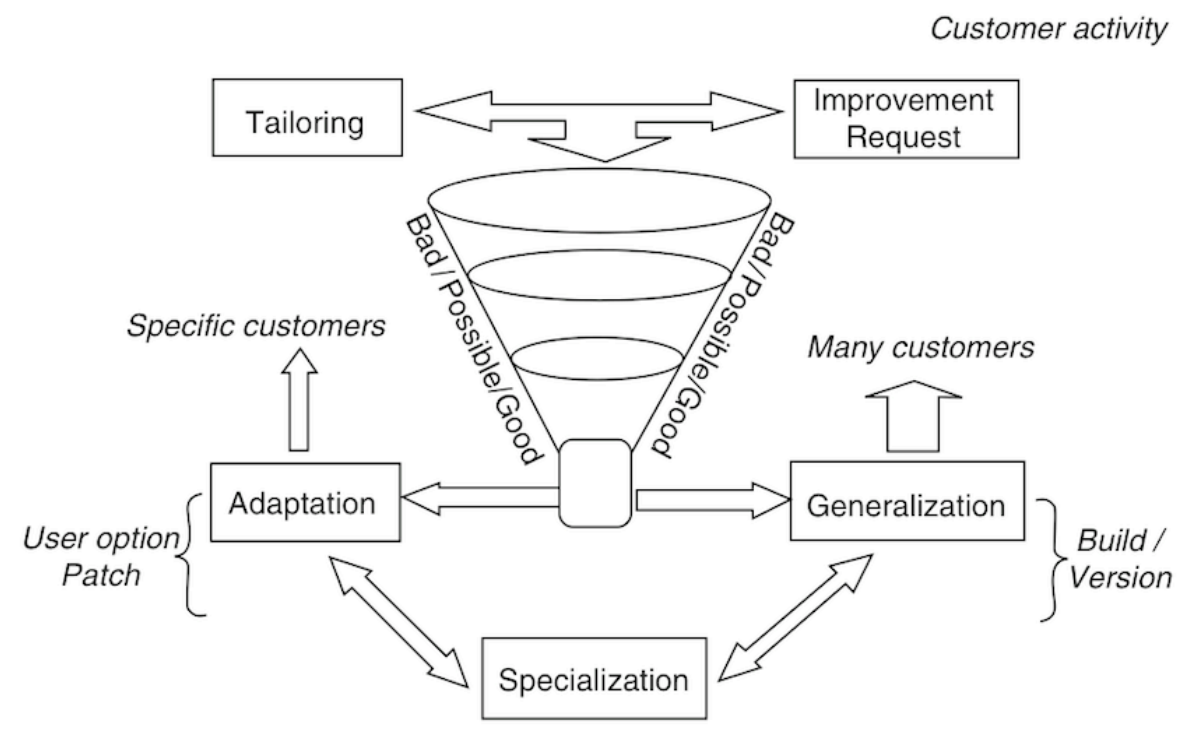

Developer activity

Figure 4: Model of mutual development in collaborative knowledge creation where the customer and developer activities co-evolve. The arrows indicate dependencies

The overall (integrated) development process is an elaboration of specialization (refinement), adaptation (domain specification), and generalization (one too many instances), starting with a stable (non-optimal) version that is gradually improved by uptakes of locally developed extensions, user options, and patches. These are initiated and/or informed by customers through improvement requests and end-user tailoring, and are categorized as good, possible, or bad. Those that are good or possible (i.e. paid for) will be part of the new builds. When multiple builds become unwieldy (i.e. too many different sites to coordinate), the system is rebuilt in-house. The new system may be introduced as a new version (released) if it will benefit the company and not jeopardize existing customer contracts, and interaction between the stages is bidirectional since new versions may lead to new local development and improvement requests, which repeat the process.

The challenge explored in this case is the integration of individual and collaborative learning in computer-mediated workplace learning. The main research question raised was to understand the transitions from specific (end-user) development to general (professional) software development. This was addressed by unpacking the collaborative knowledge creation process between developers and users of a project planning tool suite and its support systems, and based on 
interviews with the key stakeholders. The result is a model of mutual development depicted in Figure 4.

Critical to the success of this approach is the use of boundary objects (Star, 1990), in particular end-user modifiable objects in the interface between the individual and collaborative learning environments, here perceived as the integration of specific (EUD) and general development (PSD). The metaphor of trialogical learning is applied in this case to software products that are adaptable to specific customer sites (by the customer or for the customer by developers). The shared knowledge collaboratively created as a result of this is manifest in the software products themselves and in the record of discussions and negotiations mediated by the company's communication and information sharing systems.

\section{Conclusions and directions for further work}

The two cases presented demonstrate examples of knowledge management and organizational learning practices transformed into a collaborative learning and knowledge creation process that extended outside the companies studied (i.e. to involve customers). In each we identified learning as a "side effect" or process in parallel with primary work processes. This type of learning was conceptualized as "secondary work" in the ServiceCompany case, and further development of existing products and practices in the software product development company case.

More specifically, the first case explored the opportunities for CSCL at work in the following way: collaboration during information seeking (i.e., with colleagues, during staff meetings, and in interaction with customers). Moreover, in addition to collaboration with colleagues and more experienced people, searching for information in information repositories (catalogs, product sheets, web pages) and interacting with physical objects (post-it notes, tagged products) provide opportunities for learning on demand. In these situations the envelope for learning is small (customer service work does not leave much space for learning on demand), and multiple means for information seeking being in place is essential. When one means does not work, the attendant seeks out one of the alternatives. This is partly a result of the fact that secondary work is not mandated by one method. Therefore, information seeking must be adaptable to different users' needs and preferences, which varied according to age group and computer proficiency in the company we studied. Adaptation was supported by alternatives to choose from.

The second case explored CSCL at work in the form of enabling active users (customers of a software manufacturing house) to contribute to the expansion of the product line and organizational learning of the company. As the company develops software products for the open market, it benefits from feedback from its customers. These include improvement requests and local adaptations. The company followed up those suggestions that were judged to be good (e.g. an innovative new feature of general applicability) or regarded as possible to do (e.g. an adaptation for a specific customer). The case demonstrated trialogical learning in a business context, an approach to CSCL developed in the KP lab project. (Moen, Mørch \& Paavola, 2012). Collaborative learning is attributed to the knowledge collaboratively created in the developer-user constellation in conjunction with 
improving upon project-planning software. The locally adapted version of a shared product provides a model of individual learning for the end users.

Based on the work presented, open issues for further work include:

- Develop domain-specific inquiry models for different business domains,

- Creating a model of technology adoption that accounts for participatory design, end-user development, and application evolution with the diffusion of innovation model,

- Transform design-based research into a methodology for continuous assessment to sustain workplace learning innovations beyond the research project,

- Explore opportunities for cultures of participation in workplace communities (e.g., identify cases and carry our empirical studies),

- Continue to explore the potential of social media to serve as a backbone for CSCL at work technology. Our current efforts towards this are to evaluate the potential of Second Life for training military officers in intercultural communication (for service abroad), and integrating Facebook with existing e-learning applications for training in the (supermarket) retail business,

- Identify and describe a third type of work, "reflective practice," positioned between secondary work and education, to improve the gap closing of work and learning,

- Continue to invent new teaching methods and courses for educational institutions adopted from problem solving in the professions (PBL, inquiry, etc.) to make education more responsive to the needs of working life requirements, such as training in "critical thinking"

- Identify and study intermediate stages between collaborative learning and individual learning

- Carry out research with methods other than interview and questionnaire to capture the more fine-grained aspects of user data in workplace learning (e.g., interaction analysis, thinking aloud protocols, social network analysis)

- Provide design-inspired models of the non-visible stages of the (internal) learning process, which builds on boundary objects in collaborative learning

- Design computer based boundary objects that are truly plastic (i.e. end-user modifiable and extensible) for the purposes of translation, transformation, and expansion, drawing on previous research in end-user development and activity theory.

\section{Acknowledgements}

The author thanks his former students and colleagues at InterMedia who contributed to the research: Camilla Brynhildsen, Bård Ketil Engen, Mari Ann Skaanes, and Ida Tødenes, who studied the information seeking behavior of gasoline station workers; and Renate Andersen, Shazia Mushtaq, and Kathrine Nygård, who studied the collaborative interaction of professional and amateur software developers. Further, the author is grateful to Gerhard Fischer and Isa Jahnke for an invitation to submit this paper to the Springer volume on CSCL at work. The author received financial support from the Research Council of Norway 
(Learning at work project, 2001-4) and the European Commission's Framework 6 program (Knowledge practices, KP-Lab, project, 2006-11).

\section{References}

Andersen, R., \& Mørch, A. I. (2009). Mutual Development: A case study in customer-initiated software product development. In V. Pipek, M.B. Rosson, B. de Ruyter \& V. Wulf (Eds.), Proceedings 2nd Int'l Symposium on End User Development (pp. 31-49). Berlin, Germany: Springer.

Arnseth, H.C. \& Ludvigsen, S. (2006). Approaching institutional contexts: Systemic versus dialogical research in CSCL. International Journal of Computer-Supported Collaborative Learning, 1(2), 167-185.

Bereiter, C., Scardamalia, M., Cassells, C., \& Hewitt, J. (1997). Postmodernism, knowledge building, and elementary science. Elementary School Journal, 97(4), 329-340.

Cheng, B., Wang, M., Mørch, A. Chen, N.-S. \& Kinshuk (2012). Research on elearning in the workplace 2000-2010: A thematic analysis of the literature, submitted for publication to journal.

Collins, A., Joseph, D., \& Bielaczyc, K. (2004). Design research: theoretical and methodological issues. The Journal of the Learning Sciences, 13(1), 15-42.

Derry, S.J., Pea, R.D., Barron, B. Engle, R.A., Erickson, F., Goldman, R., Hall, R., Koschmann, T., Lemke, J.L., Sherin, M.G. \& Sherin, B.L. (2010). Conducting video research in the learning sciences: Guidance on selection, analysis, technology and ethics. Journal of the Learning Sciences, 19, 3-53.

Dillenbourg, P., Baker, M., Blaye, A. \& O'Malley, C. (1996). The evolution of research on collaborative learning. In E. Spada \& P. Reiman (Eds.), Learning in humans and machine: Towards an interdisciplinary learning science (pp. 189-211). Oxford, UK: Elsevier.

Engeström, Y. (2001). Expansive learning at work: An activity theoretical reconceptualization. Journal of Education and Work, 14(1), 133-156.

Enyedy, N. \& Hoadley, C.M. (2006). From dialogue to monologue and back: Middle spaces in computer-mediated learning, Computer-Supported Collaborative Learning, 1(4), 413-439.

Fischer, F., Mandl, H., Haake, J., \& Kollar, I. (Eds.). (2007). Scripting computersupported collaborative learning: Cognitive, computational and educational perspectives. New York, NY: Springer.

Fischer, G. (1995). Supporting learning on demand with design environments. In L. Birnbaum (Ed.), Proceedings of the First International Conference on the Learning Sciences (pp. 165-172.). Association for the Advancement of Computing in Education.

Fischer, G. (2003). Working and learning when the answer is not known. Keynote address at European Conference on CSCW, Helsinki, September, 2003. URL: http://13d.cs.colorado.edu/ gerhard/presentations/ecscw-keyn-slides-final.pdf

Fischer, G. (2011). Understanding, fostering, and supporting cultures of participation. Interactions, 18(3), 42-53. 
Fischer, G., Lemke, A. C., Mastaglio, T., \& Morch, A (1991). The role of critiquing in cooperative problem solving. ACM Transactions on Information Systems, 9(2), 123-151.

Florida, R. (2002). The rise of the creative class: And how it's transforming work, leisure, community and everyday life. New York, NY: Perseus Book Group.

Gräs, M.G. (2011). Kinesere skal lære på den danske måde (The Chinese want to learn according to the Danish way). Dr.dk (online Danish newspaper) posted Nov.18, 2011. URL: http://www.dr.dk/Nyheder/Penge/2011/11/17/085337.htm

Hakkarainen, K. (2003). Emergence of progressive inquiry culture in computersupported collaborative learning. Learning Environments Research, 6(2), 199220.

Hoppe, U., Ogata, H., \& Soller, A. (Eds.) (2007). The Role of Technology in CSCL: Studies in Technology Enhanced Collaborative Learning, New York, NY: Springer.

Jenkins, H. (2009). Confronting the challenges of participatory cultures: Media education for the 21st century. Cambridge, MA: MIT Press.

Jordan, B. \& Henderson, A. (1995). Interaction analysis: Foundations and practice, The Journal of the Learning Sciences, 4, 39-103.

Kaplan, A.M. \& Haenlein, M. (2010). Users of the world, unite! The challenges and opportunities of Social Media. Business Horizons, 53 (1), 59-68.

Kienle, A. \& Wessner, M. (2005). Our way to Taipei: An analysis of the first ten years of the CSCL community. Proceedings of CSCL 2005 (pp. 262-271). International Society of the Learning Sciences.

Krange, I. \& Ludvigsen, S. (2009). The historical and situated nature of design experiments: Implications for data analysis. Journal of Computer Assisted Learning, 25(3), 268-279.

Law, N. (2002). Scaffolding scientific conceptualization: Multiple representation and multilevel visualization using an iconic modeling tool. In Proceedings ICCE 2002 (pp. 257-261). Auckland, New Zealand: IEEE Press.

Leinonen, T., Virtanen, O., Hakkarainen, K., \& Kligyte, G. (2002). Collaborative discovering of key ideas in knowledge building. In G. Stahl (Ed.), Proceedings Computer Support for Collaborative Learning (CSCL 2002) conference. Boulder, CO, January 7-11, 10 pages.

Ludvigsen, S., \& Mørch, A. (2010). Computer-supported collaborative learning: Basic concepts, multiple perspectives, and emerging trends. In B. McGaw, P. Peterson \& E. Baker (Eds.), The International Encyclopedia of Education, Volume 5 (pp. 290-296). Oxford, UK: Elsevier.

Moen, A., Mørch, A.I. \& Paavola, S. (2012). Collaborative knowledge creation: Practices, tools, concepts. Rotterdam, The Netherlands: Sense Publishers. In press.

Mørch, A.I. \& Andersen, R. (2010). Mutual development: The software engineering context of end-user development. Journal of Organizational and End User Computing, 22(2), 36-57. 
Mørch. A.I. and Engen, B.K. (2008). Integrating e-learning with performance support: Workplace learning as extension of work. Paper presented at $1^{\text {st }}$ Int'1 Conf. on E-learning in the Workplace. Teachers College, Columbia University, New York.

Mørch, A. I., Engen, B. K., \& Åsand, H.-R. (2004). The workplace as a learning laboratory: The winding road to e-learning in a Norwegian service company. In A. Clement, et al. (Eds.), Proceedings of PDC’2004 (pp. 141-151). New York, NY: ACM Press.

Mørch A., Jondahl, S., \& Dolonen, J. (2005). Supporting conceptual awareness with pedagogical agents, Information Systems Frontiers, special issue on Computer Supported Collaborative Learning Requiring Immersive Presence, 7(1), 39-53.

Mørch, A.I., Nygård, K.A., \& Ludvigsen, S.R. (2009). Adaptation and generalisation in software product development. In H. Daniels, et al. (Eds.), Activity theory in practice: Promoting learning across boundaries (pp. 184205). , London, UK: Routledge.

Mørch, A.I. \& Skaanes, M.A. (2010). Design and use of an integrated work and learning system: Information seeking as critical function. In S. Ludvigsen, A. Lund, I. Rasmussen, \& R. Säljö, (Eds.), Learning across sites: New tools, infrastructures and practices (pp. 138-155). London, UK: Routledge.

Netteland, G. (2008). E-learning for change in a large organization: Identifying problems and opportunities in the implementation of e-learning. PhD thesis, Department Information Science and Media Studies, University of Bergen, Norway.

Netteland, G., Wasson, B., \& Mørch, A.I. (2007). E-learning in a large organization: A study of the critical role of information sharing. Journal of Workplace Learning, 19(6), 392-411.

Paavola, S. \& Hakkarainen, K. (2005). The knowledge creation metaphor: An emergent epistemological approach to learning. Science and Education, 14, 537-557.

Rogers, E. M. (2003). Diffusion of innovations: Fifth edition. New York, NY: Free Press.

Rommetveit, R. (1992): Outlines of a dialogically based social-cognitive approach to human cognition and communication. In A.H. Wold, (Ed.), The Dialogical alternative: Towards a theory of language and mind (pp. 19-44). Oslo, Norway: Scandinavian University Press.

Servage, L. (2005) Strategizing for workplace e-learning: Some critical considerations. Journal of Workplace Learning, 17(5/6), 304-317.

Sfard, A. (1998). On two metaphors for learning and the dangers of choosing just one. Educational Researcher, 27(2), 4-13.

Simon, H.A. (1996). The sciences of the artificial: Third edition. Cambridge MA: MIT Press.

Stahl, G. (2006). Group cognition: Computer support for building collaborative knowledge. Cambridge, MA: MIT Press. 
Stahl, G., Koschmann, T., \& Suthers, D. (2006). Computer-supported collaborative learning. In R.K. Sawyer, (Ed.) The Cambridge handbook of the learning sciences. Cambridge, UK: Cambridge University Press.

Star, S.L. (1990). The structure of ill-structured solutions: Boundary objects and heterogeneous distributed problem solving. In L. Gasser and M.N. Huhns (Eds.), Distributed artificial intelligence: vol. 2 (pp. 37-54). San Francisco, CA: Morgan Kaufmann Publishers.

Strauss, A. (1988). The articulation of project work: An organizational process. The Sociological Quarterly, 29, 163-178.

Suthers, D. \& Hundhausen, C. (2003). An empirical study of the effects of representational guidance on collaborative learning. Journal of the Learning Sciences, 12(2), 183-219.

Tynjälä, P. \& Häkkinen, P. (2005). E-learning in work organizations: Theoretical underpinnings, practical experiences and pedagogical challenges. Journal of Workplace Learning, 17(5/6), 318-336.

Vygotsky, L. S., (Author) \& Cole, M., (Ed.) (1978). Mind in society: The development of higher psychological processes. Cambridge, MA: Harvard University Press.

Wang, M. (2011). Integrating organizational, social, and individual perspectives in web 2.0-based workplace e-learning, Information Systems Frontiers, 13(2), 191-205.

Wenger, E. (2000). Communities of practice and social learning systems. Organization, 7(2), 225-246.

Wertsch, J.V. (1991). Voices of the mind: A socio-cultural approach to mediated action. Cambridge, MA: Harvard University Press. 